\title{
UNUSUAL NEUROLOGICAL DAMAGE AFTER FRACTURE-DISLOCATION OF THE LUMBAR SPINE
}

\author{
A CASE Report \\ By Pesi B. Chaca and S. C. Loong \\ Outram Road General Hospital, Singapore, and \\ Thomson Road General Hospital, Singapore
}

VARIED upper levels of paraplegia due to simultaneous cord and root damage in case of fracture-dislocations of the thoraco-lumbar spine have been reported by Holdsworth and Hardy (1953) and Holdsworth (1963, 1970) in the past. In such cases the root injuries invariably produce sensory as well as motor paralysis in the distribution of the damaged nerve roots. The following case report is most unusual in that unilateral flaccid paralysis of all muscles innervated by the lumbar and sacral nerve roots without any sensory involvement resulted from a fracture-dislocation of the lumbar spine. We have been unable to trace any report of a similar injury in the available literature.

Case Report. A 27-year-old female was admitted to another hospital in a shocked and unconscious state after being hit by a car from behind. It was then noted that she had sustained multiple lacerations over the head and face, deep abrasions over both iliac crests, a fracture of the right anterior superior iliac spine and extensive bruising of the inner side of the right thigh and the vulva. She regained consciousness shortly after the admission and was found to be unable to pass urine. An indwelling catheter was inserted which was removed after 24 hours. Subsequently she was able to void $250 \mathrm{ml}$. of urine once. She again developed retention of urine for 24 hours and it was then noticed that she was unable to move her left lower limb. Detailed record of the neurological condition was not made. A radiograph of the lumbar spine revealed a fracture through the upper part of the body and both superior articular processes of the second lumbar vertebra with a complete forward displacement of the lumbar vertebral column distal to the site of the fracture (fig. I). She was then transferred under our care. A thorough neurological examination revealed that there was a complete flaccid paralysis of all the muscles of the left lower limb with loss of knee, ankle and plantar reflexes.

There was no sensory impairment in both the lower limbs and the saddle area. Voluntary movements were present at all joints in the right lower limb but a detailed grading of individual muscles was not possible due to pain. The knee and ankle jerks were absent and the plantar reflex could not be elicited. The bladder was distended and she was unable to pass urine although she felt some bladder sensation. The tone of the anal sphincter was slightly less than normal. Continuous bladder drainage was installed with an indwelling catheter. Under a general anaesthetic with the patient prone, the fracture dislocation was reduced without difficulty by lifting the pelvis and the lower lumbar spine backwards. Meurig Williams plates were then applied from the twelfth thoracic to the fourth lumbar spinous processes (figs. 2 and 3 ). The post-operative recovery was uneventful and the wound healed primarily except for a small area of superficial breakdown in the upper part. The indwelling catheter was removed on the seventh day after the operation and she was able to void urine normally. The anal sphincter tone improved and after an initial period of constipation she had normal regular bowel movements. She was nursed in bed for 3 months. There was no appreciable change in her 
Fig. I

Antero-posterior and lateral radiographs showing fractures of the superior articular facets and the upper surface of the body of second lumbar vertebra with forward displacement of lower lumbar, vertebrae.

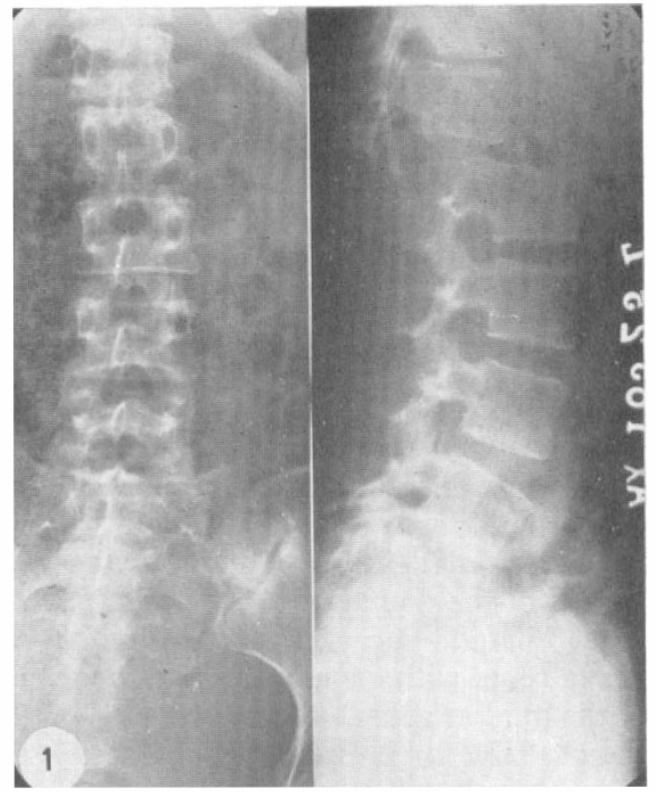

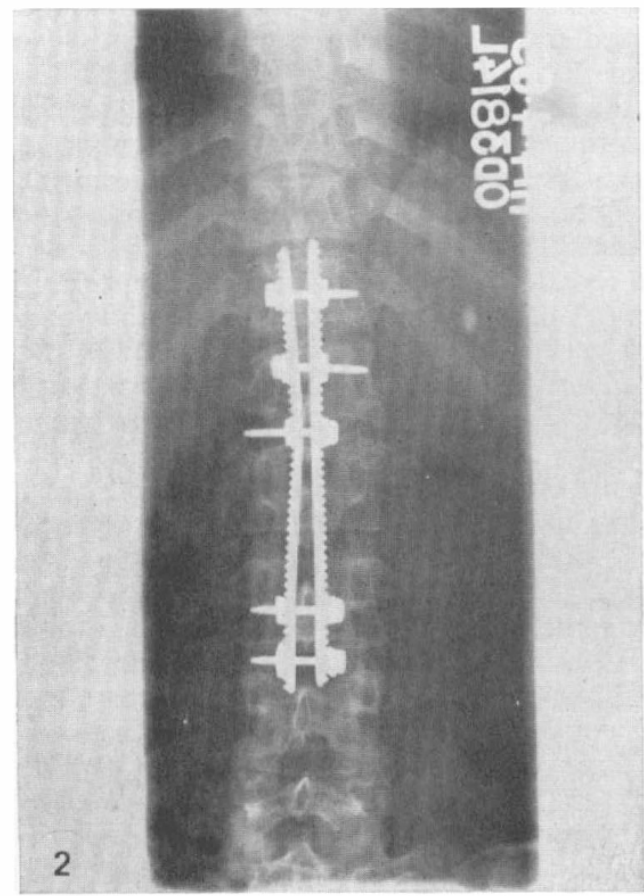

FIG. 2

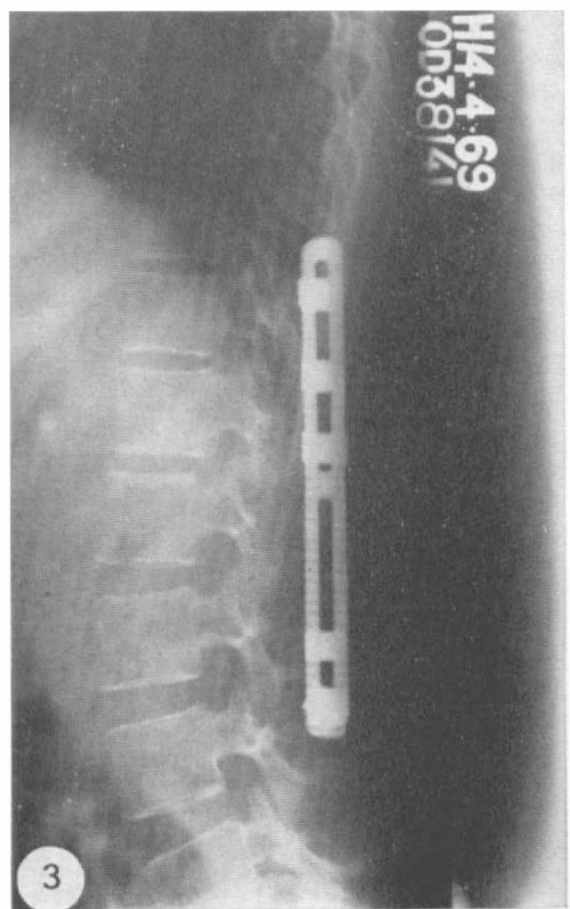

FIG. 3

Figs. 2 and 3.-Antero-posterior and lateral radiographs showing anatomical reduction and internal fixation with Meurig Williams plates. 
neurological state. Complete motor paralysis of the left lower limb, absence of knee and ankle jerks on both sides and absence of plantar reflex on the left side persisted. Radiographs of the lumbar spine revealed that the fracture of the upper surface of the body of the second lumbar vertebra was united and there was a fair amount of paravertebral new bone formation on the right side between the first and second lumbar vertebrae (figs. 4 and 5 ).

She was allowed to walk using a polythene body-jacket, an above-knee ischial-bearing caliper on the left side and a pair of elbow crutches. The polythene body jacket was discarded after 4 months. At the last examination 17 months after the injury there was

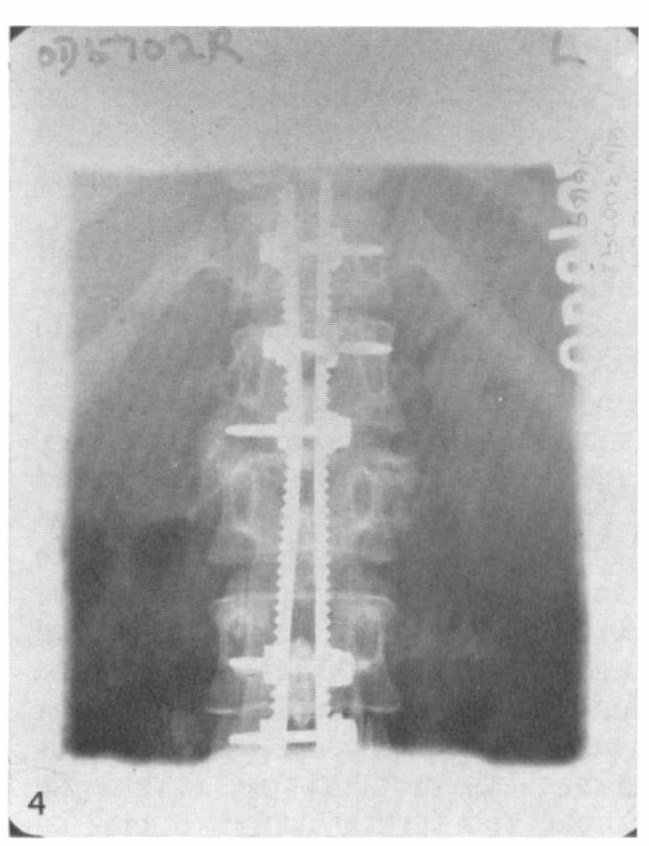

Fig. 4

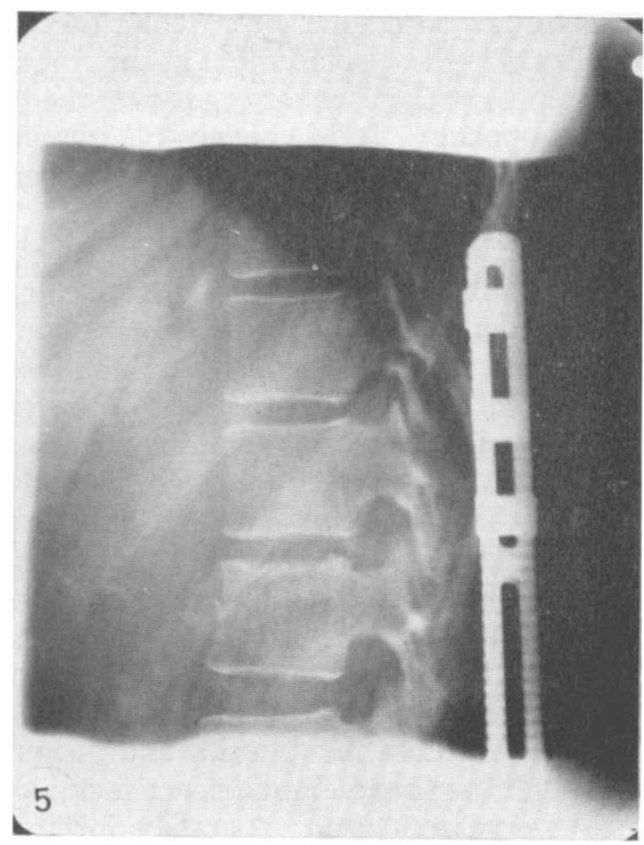

FIG. 5

Figs. 4 and 5. Antero-posterior and lateral radiographs 3 months after the injury. The fracture of the second lumbar vertebral body has united soundly. There is paravertebral new bone formation on the right side leading to interbody fusion between the first and second lumbar vertebrae.

still complete flaccid paralysis and marked wasting of all muscles of the left lower limb with absence of knee, ankle and plantar reflexes. The right lower limb was completely normal except for the absence of the knee and ankle jerks. Appreciation of touch, pinprick, temperature, vibration, joint position, two-point discrimination and figure-writing was normal in both lower limbs, including the saddle area, and she had full control over her bladder and rectum. Sampling of the left extensor digitorum brevis, tibialis anterior, gastrocnemius, soleus and quadriceps with co-axial needle electrodes showed scanty fibrillation but no voluntary activity. Sampling of the corresponding muscles on the right side showed no abnormality. Nerve action potentials recorded from the left lateral popliteal and posterior tibial nerves at the knee were 3 uv and 5 uv respectively. These values were at the lower limit of a wide normal range. This was consistent with the observation by Gilliatt et al. (I96I) that when the motor fibres alone are eliminated by 
disease in the anterior tibial nerve, the sensory fibres could still be excited in sufficient numbers to give rise to a recordable action potential. The radiographs revealed bony fusion between the first and the second lumbar vertebrae on the right side.

\section{DISCUSSION}

Two very interesting features were revealed in this case. Firstly the fracture: dislocation was produced from a shearing force as described by Holdsworth (1970) which resulted into slicing of the upper surface of the second lumbar vertebra and fracture of both superior articular processes. However, the unusual feature of the injury was the displacement at the fracture site. It is more common for the upper vertebrae to displace forwards over the lower vertebrae while in this case it was just the opposite. It is conceivable that the force that knocked her from behind displaced the whole of the lower lumbar vertebral column and the pelvis forwards at the level of the fracture.

Secondly, despite the severe displacement, pure motor paralysis of the left lower limb and absence of right knee and ankle jerks were the only signs of neurological damage, the sensations being completely spared. It is extremely difficult to postulate the mechanism of such an incomplete neurological damage. The tip of the spinal cord reaches the level of the lower border of the first lumbar vertebra and could easily suffer traction injury in case of such a severe displacement at this level. However, it is hard to conceive that only the anterior horn cells of the lumbar and sacral cord segments on one side should suffer and the sensations be spared completely. The lower motor neurone paralysis of the left lower limb, the absence of knee and ankle jerks on the right side and the temporary impairment of the bladder and rectal control are more in favour of damage to the lumbar and sacral anterior nerve roots alone. The visceral innervation being bilateral explains the rapid recovery of the bladder and rectal functions. Below the level of the first lumbar vertebra the anterior and posterior nerve roots pass vertically downwards through the subarachnoid space forming the cauda equina (Last, I959). Since the two nerve roots run separately for a very long and vertical course, it may be possible for only the anterior roots to suffer traction injury sparing the posterior roots which carry the sensory fibres. The presence of normal mixed nerve potentials were in support of the integrity of the sensory nerve fibres (Gilliatt et al., I96I). However, the predominently unilateral affection from a forward traction force still remains difficult to explain. Lumbar puncture and myelogram were not done and therefore the possibility of a unilateral haematoma cannot be ruled out. In view of the numerous anastomotic channels between the anterior and posterior spinal arteries and the radicular branches, this unusual unilateral motor paralysis is unlikely to be due to vascular insufficiency.

\section{SUMMARY}

A case of unilateral paralysis of all muscles innervated by the lumbar and sacral roots without any sensory involvement following a fracture-dislocation of the second lumbar vertebra is described. No adequate explanation could be offered for this most unusual neurological involvement. Traction injury to the anterior nerve roots alone seems to be the most likely cause. 


\section{RÉSUMÉ}

Le cas d'une paralysie unilatérale de tous les muscles innervés par des racines lombaires et sacrées, sans atteinte sensitive a la suite d'une fracture dislocation de la deuxième vertèbre lombaire est décrit.

Aucune explication ne peut être faite pour cette atteinte neurologique inhabituelle. Une lésion par étirement des racines antérieures seule semble être la cause la plus vraisemblable.

\section{ZUSAMMENFASSUNG}

Die Autoren beschreiben einen Fall von unilateraler Lähmung aller von lumbosakralen Wurzeln innervierten Muskeln ohe Sensibilitätsstörungen als Folge einer Luxations-Fraktur des zweiten Lendenwirbels. Eine ausreichende Erklärung der neurologischen Symptomatologie wird nicht gegeben. Es wird als wahrscheinlichste Ursache eine Zerrschädigung der vorderen Spinalwurzeln angenommen.

Acknowledgments. We are most thankful to Mr. Tow Siang Hong of the University Department of Orthopaedic Surgery, Section of Clinical Photography, for the photographs and to Mr. E. W. Kong for his secretarial help.

\section{REFERENCES}

Gilliatt, R. W., Goodman, H. V. \& Willison, R. G. (196r). Fournal of Neurology, Neurosurgery and Psychiatry, 24, 305.

Holdsworth, F. W. \& HARDY, A. (I953). Fournal of Bone and foint Surgery, 35-B, 540. Holdsworth, F. W. (1963). Fournal of Bone and foint Surgery, 45-B, 6.

HoldsworTh, F. W. (1970). Fournal of Bone and Foint Surgery, 52-A, I534.

Last, R. J. (1959). Anatomy Regional and Applied. London: J. \& A. Churchill Ltd. 